\title{
Wissen Warum noch Lexika?
}

T exika bringen das, was man weiß, und das, was man nicht Lweiß, auf den Punkt. Maßstab ist der Normalverstand, manchmal auch der professionelle Verstand, der dann wiederfindet, was er nach Eigeneinschätzung eigentlich besser weiß. Die Steigerung von Lexika sind die Enzyklopädien, von Vollständigkeitsidealen getrieben und kostbar in der Aufmachung. So stehen sie in unseren Regalen, füllen Lücken im Verstand und dokumentieren den Bildungswillen ihrer Besitzer. Ist das heute, im Zeitalter von Google \& Co., noch zeitgemäß? Wenn die Welt in Bits und Bytes ins Haus kommt und auf jede Frage eine Antwort weiß, was sollen da noch Regale, gefüllt mit klugen Büchern nach Art von Lexika und Enzyklopädien? Das Wissen löst sich von seinen traditionellen Trägern - es wird virtuell, flüchtig, anonym, kein Autor, kein Herausgeber steht mehr für das Wissen ein. Ist das Wissen im Himmel, im Virtuellen, angekommen oder hat es nur die Erde, unsere Lebenswelt, verloren? Lexika und Enzyklopädien hielten das Wissen dort fest. Wird das nicht mehr sein? 